\title{
Choroid plexus papilloma in extragonadal teratoma with predominantly neurogenic elements: a case report and review of the literature
}

\author{
İsmail Saygın ${ }^{\oplus}$ Emel Çakır ${ }^{\oplus}$ Mustafa Emre Ercin ${ }^{\odot}$ \\ Department of Pathology, Karadeniz Technical University Faculty of Medicine, Trabzon, Turkey.
}

\begin{abstract}
Background. Teratoma is a germ cell tumor that develops gonadal or extragonadal. Benign or malign somatic tumors can develop in teratoma. Choroid plexus papilloma is a benign, grade I intraventricular neoplasm that occur mostly in children. Choroid plexus papilloma in a teratoma is not often seen.

Case. We present the fifth case of a choroid plexus papilloma in a teratoma in the English literature. It was extragonadal and localized on the right side of the neck. It included only neuroglial tissue.

Conclusion. It is important to separate a teratoma with normal choroid plexus from a teratoma with choroid plexus tumor. Pathologists need to be aware of this entity in the distinction from other papillary neoplasms that may be primary or metastatic.
\end{abstract}

Key words: choroid plexus papilloma, teratoma, neuroglial tissue, extragonadal, newborn.

Teratoma is a germ cell neoplasm which has any combination of ectodermal, mesodermal and endodermal elements. The frequency of teratoma is 1 in 4,000 live births and $1-2 \%$ of the cases seen in the head and neck region. ${ }^{1}$ Approximately $75 \%$ of this tumor group are mature teratomas, and about $12 \%$ of the cases are malignant and lethal. ${ }^{2}$ Head and neck teratomas are most commonly seen at the cervical region, oropharynx is the second most common location. Congenital cervical teratoma is approximately $3 \%$ of the teratomas seen in childhood/infancy. ${ }^{3}$ Since head and neck teratomas frequently presents with respiratory distress, surgeons should be aware of the clinical presentation and pathology of the teratoma.

Choroid plexus papillomas (CPP) are benign and slow-growing tumors derived from choroid plexus epithelium. ${ }^{4}$ They are predominantly

$凶 \quad$ İsmail Saygin

ismailsaygin@ktu.edu.tr

Received 2nd July 2018, revised 23rd July 2018,

29th August 2019, accepted 21st October 2019. seen in children, and in the lateral ventricle, while they are seen in the fourth ventricle in adult. Many different localizations of the tumor have been documented. ${ }^{5}$ The incidence of CPP is $0.3-0.6 \%$ of all brain tumors; $2-4 \%$ of the cases occur under the age of 15 , and $10-20 \%$ of the cases occur within the first year of life.Teratoma is an unusual location for CPP. Four cases of CPP located in teratoma have been publishedin the literature so far. ${ }^{6}$ All these cases were found in ovarian teratoma. Unlike the other cases, our case was at the cervical region.

Up to $90 \%$ of childhood teratomas contain derivatives from all three embryonic germ layers. Though teratomas develop from the three germ cell layers, some reports showed that they may arise from a single germ cell. The present teratoma included totally mature neuroglial tissue.

\section{Case Report}

A female neonate born with cesarean section at 39 weeks of age weighting 3350 grams had a mass 
on her neck at birth. The voluminous cervical mass was detected prenatally. It was followed up by a gynecologist until birth. She was operated on two weeks after birth. On postnatal magnetic resonance imaging (MRI) a $9 \mathrm{~cm}$ diameter mass with cystic and solid components was observed on the right side of the neck. It extended from the parapharyngeal region to the subcutaneous soft tissue. Teratoma, rhabdomyosarcoma and neuroblastoma were considered in the differential diagnosis. Tumor markers were within normal level. The lesion was removed by protecting vital organs and skin. There was no complication during the postoperative period. Macroscopically; the mass had cystic and solid areas. Microscopically; a CPP was found in the cyst. The diameter of the lesion was 0,6 $\mathrm{cm}$. It was arranged of papillary structures with fibrovascular cores. Papillary structures showed complexity and there were acinar structures in some areas (Fig. 1). Epithelium of the CPP showed variably pseudostratification, surface epithelium of it was flat, and nuclei were oval and elongated (Fig. 2). Necrosis, mitosis and solid pattern was not observed. The other areas consisted of mature neuroglial tissue entirely (Fig. 3). Neuroglial tissue was hypercellular in some areas, but non-neoplastic. Immunohistochemical study showed that neuroglial tissue was positive for Alpha Thalassemia/Mental Retardation Syndrome X-Linked (ATRX), Glial fibrillary acidic protein (GFAP), Oligodendrocyte Transcription Factor 2 (OLIG2), and negative for The p53 gene (P53) and Isocitrate dehydrogenase 1 (IDH1). Antigen KI-67 (Ki67) index was very low.

Written informed consent was obtained from the patient's parents for publication.

\section{Discussion}

The teratoma of the head and neck region can shows unpredictable behavior and dramatic clinical presentation. Because of the potential for rapid growth of teratomas and as a result airway compression, the treatment of cervical and nasopharyngeal teratomas is immediate excision. Cervical teratoma is not common. In the literature 217 cases of cervical teratoma have been reported until 2009, and $90 \%$ of the cases were diagnosed in the pediatric population. ${ }^{7}$

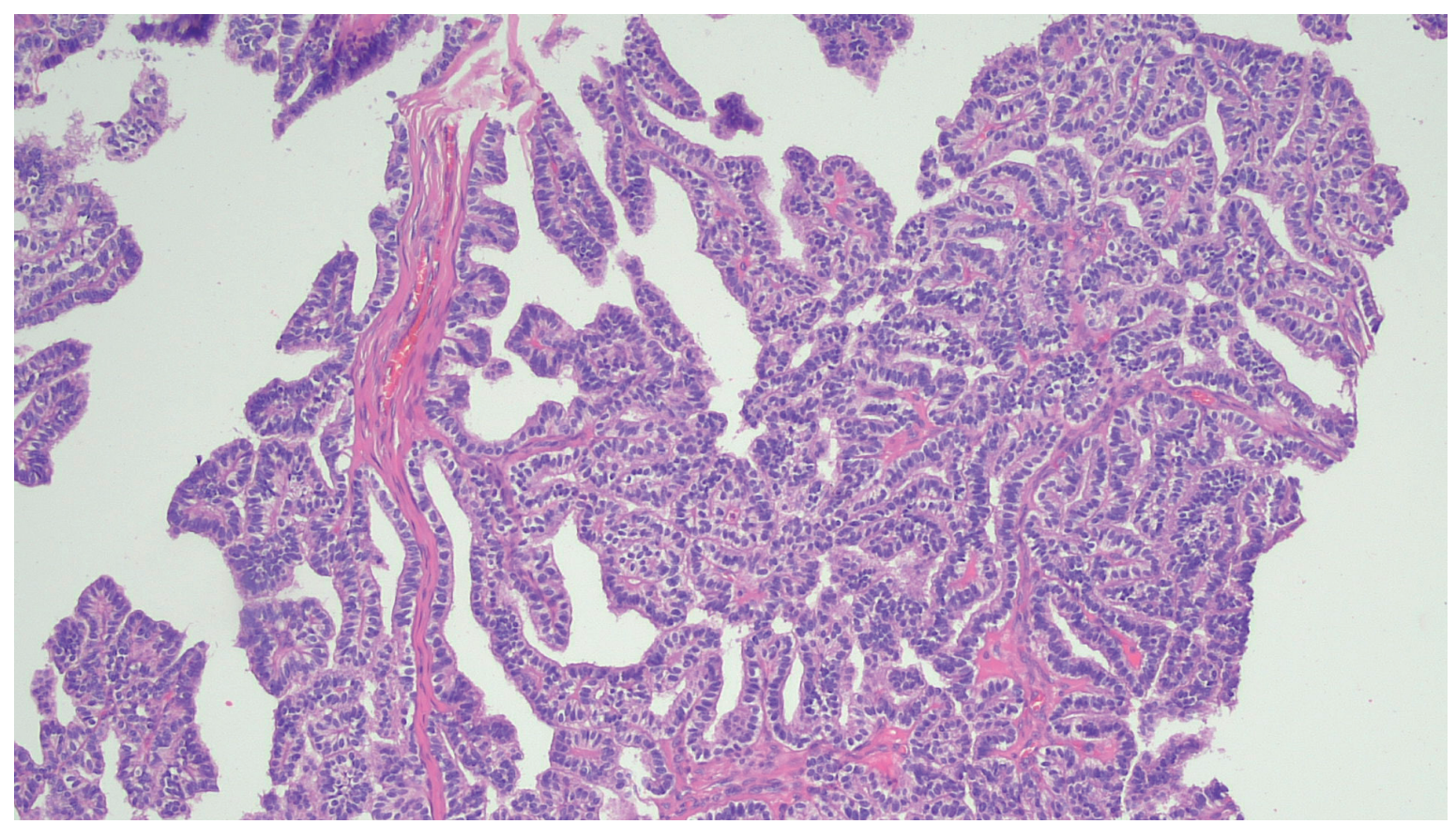

Fig. 1. HE X 200: Choroid plexus papilloma; papillary structures with fibrovascular cores and acinar structures in some areas. 


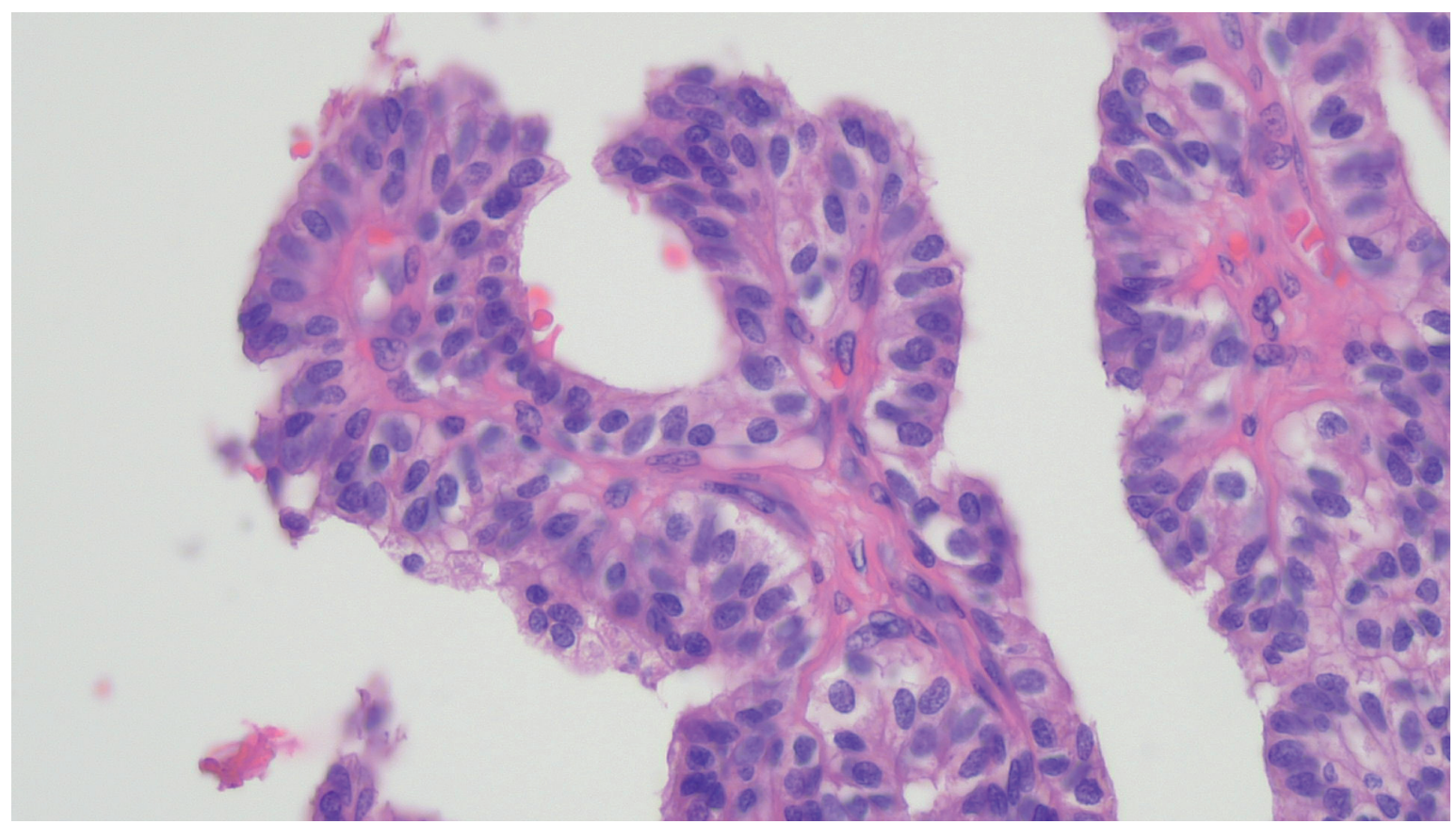

Fig. 2. HE X 400: Choroid plexus papilloma; variable pseudostratification of epithelium, flat surface epithelium, oval and elongated nuclei.

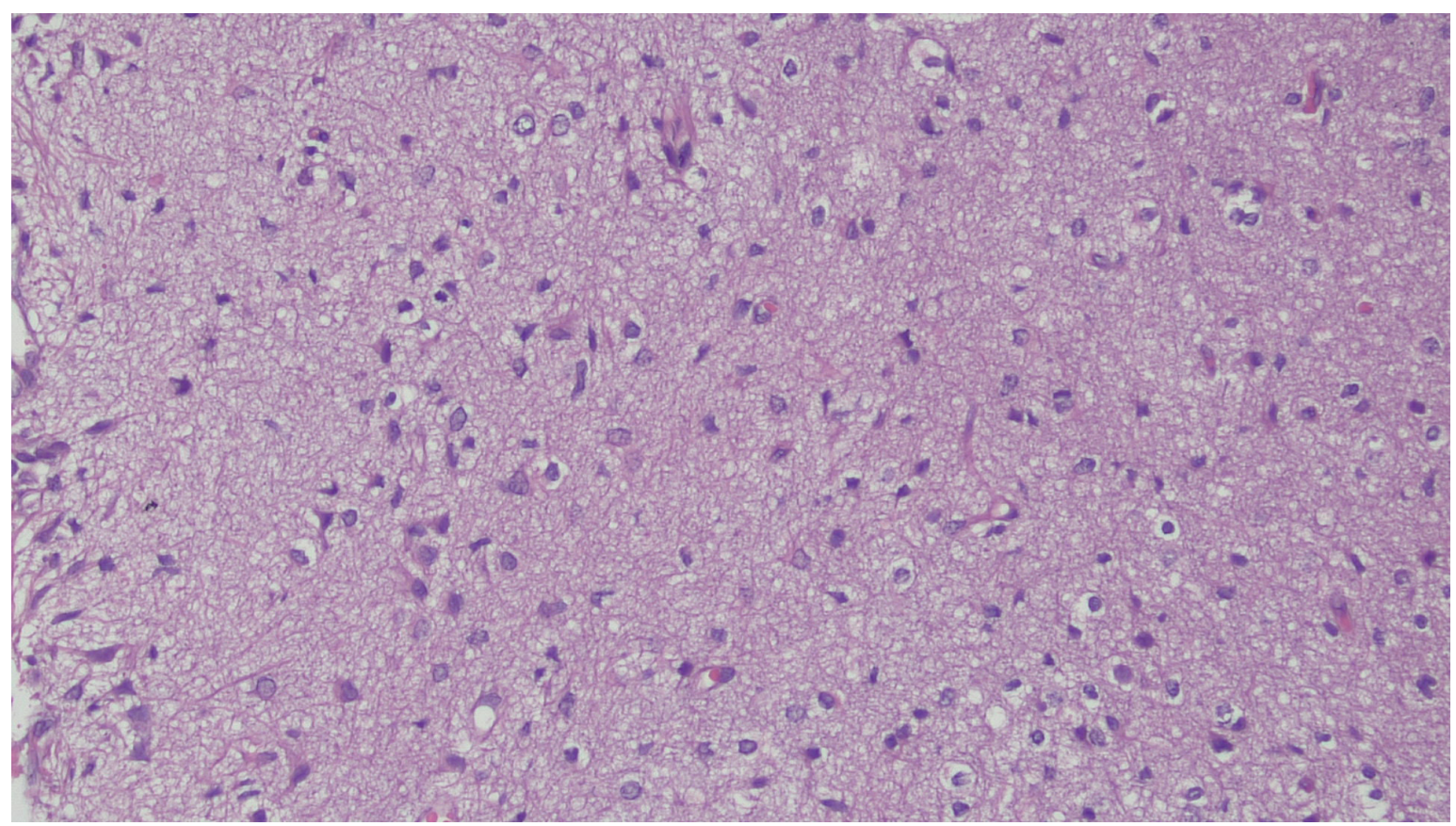

Fig. 3. HE X 200: Neuroglial tissues in different regions of teratoma (hypercellular and hypocellular areas).

The present case included CPP in teratoma of the head and neck region.

Choroid plexus in teratoma is commonly seen. It is important to separate a teratoma with choroid plexus from a teratoma with choroid plexus tumor. CPP contains more complex papillary architecture than non-neoplastic choroid plexus, and epithelium is flat in comparison with normal cobblestone-like surface. Only 
four CPP in teratoma cases have been reported so far (Table I). In the present case, the diameter of the papilloma was very small, and was only visible at microscopic examination. In our case there was a delicate fibrovascular stalk covered by a single layer of cuboidal epithelial cells, arranged in a papillary configuration with fingerlike projections of tissue in the teratoma. The nucleus of the epithelium was slightly elongated.

Monodermal teratoma which includes only neuroglial tissue is uncommon in the literature. Akbulut et al. ${ }^{8}$ described an ovarian teratoma that mainly consists of neurogenic elements including glial tissue, cuboidal cells lining the lumen of the cyst resembling ventricular ependyma, melanotic cells, ganglion cells, peripheral nerve and choroid plexus. Sharma et al. $^{9}$ reported a teratoma case that was predominantly composed of neurogenic tissue in the retroperitoneal region. Williams et al. $^{10}$ presented a monodermal teratoma which was named neurogenic ovarian cyst. It included neuroglial tissue with astrocytes, occasional Rosenthal fibers, oligodendrocytes, ependymal cells, scattered neurons with an overlying arachnoid layer and cerebellar tissue components. Our case consisted of only neuroglial tissue which included astrocyte, oligodendrocyte and choroid plexus. But it was not a monodermal teratoma because of the presence of choroid plexus. The choroid plexus has dual embryonic origin, with the choroid plexus epithelium originating from the ectoderm and the central stroma from the mesoderm. ${ }^{11}$

Our case was unique with its neuroglial component that includes CPP. CPP should be considered in the differential diagnosis with other papillary neoplasms which could be primary or metastatic such as serous, clear cell or endometroid gynecologic tumours, mesothelioma, papillary thyroid carcinoma, and lung adenocarcinoma. ${ }^{12}$

Immunohistochemically, choroid plexus epithelium-derived tumors react with pancytokeratin and epithelial membrane antigen (EMA), sometimes with vimentin, S-100 protein and synaptophysin. Focal GFAP reaction can be seen in epidermal differentiated choroid plexus tumor. But none of them are used in the differentiation of primary choroid plexus tumor from metastasis.

Two specific markers of choroid plexus tumor have been recently described.Kir7.1, a potassium inwardly-rectifying channel family member that may play a role in the transepithelial transport

Table I. Cases of choroid plexus papilloma in teratoma.

\begin{tabular}{|c|c|c|c|c|c|c|c|}
\hline $\begin{array}{l}\text { Case and } \\
\text { reference }\end{array}$ & Year & Age & Localization & Diagnosis & Teratomatous elements & Size & Treatment \\
\hline $\mathrm{I}^{14}$ & 2006 & 14 & Ovary & $\mathrm{CPP}$ & $\begin{array}{c}\text { Lungparenchyma, } \\
\text { neuropil }\end{array}$ & ND & ND \\
\hline $\mathrm{II}^{15}$ & 2011 & 26 & Ovary & $\mathrm{ACPP}$ & $\begin{array}{l}\text { Skin withadnexal } \\
\text { structures, } \\
\text { neuroglialelements, } \\
\text { adiposetissue }\end{array}$ & $9 \times 7 \times 7 \mathrm{~cm}$ & Cystectomy \\
\hline $\mathrm{III}^{16}$ & 2013 & 32 & Ovary & $\mathrm{CPP}$ & $\begin{array}{l}\text { Skeletalmuscle, } \\
\text { Adiposetissue }\end{array}$ & $8 \times 3 \mathrm{~cm}$ & Oophorectomy \\
\hline $\mathrm{IV}^{6}$ & 2015 & 23 & Ovary & $\mathrm{CPP}$ & $\begin{array}{l}\text { Bone, cartilage, skin } \\
\text { withadnexal structures, } \\
\text { respiratorytype } \\
\text { epithelium, ependym }\end{array}$ & $22.5 \times 20.5 \mathrm{~cm}$ & $\begin{array}{c}\text { Salpingo- } \\
\text { oophorectomy }\end{array}$ \\
\hline Present case & 2018 & Newborn & Neck & $\mathrm{CPP}$ & Neuroglialelements & $10 \times 9,5 \times 8,5$ & Resection \\
\hline
\end{tabular}

ACPP: atypical choroid plexus papilloma, CPP: choroid plexus papilloma, ND: not described. 
of potassium. Stanniocalcin-1, a glycoprotein normally expressed in human choroid plexus that might participate in the regulation of cerebrospinal fluid calcium levels. Both normal choroid plexus and choroid plexus neoplasm react for these two immunohistochemical markers. ${ }^{13}$ Therefore, Kir7.1 and Stanniocalcin-1 are sensitive and specific diagnostic markers for choroid plexus tumor. They are used in the differentiation of metastasis from choroid plexus tumor.

A choroid plexus papilloma located in a teratoma at neck region was presented. Pathologists need to be aware of this entity in the distinction from other papillary neoplasms that may be primary or metastatic.

\section{REFERENCES}

1. Nelson BL. Teratoma. In: Thompson LDR, Wenig BM (eds). Diagnostic Pathology: Head and Neck (2nd ed). Philadelphia: Elsevier, 2016: 409-411.

2. Maitra A. Diseases of infancy and childhood. In: Kumar V, Abbas AK, Aster JC (eds). Robbins and Cotran Pathologic Basis of Disease (9th ed). Philadelphia: Saunders, 2015: 474-475.

3. Hasiotou M, Vakaki M, Pitsoulakis G, et al. Congenital cervical teratomas. Int $\mathrm{J}$ Pediatr Otorhinolaryngol 2004; 68: 1133-1139.

4. Paulus W. Brandner S. Hawkins C. Tihan T. Choroid plexus tumours. In: Louis DN, Ohgaki $\mathrm{H}$, Wiestler OD, Cavenee WK (eds). WHO Classification of Tumours of the Central Nervous System (Medicine) (4th ed). World Health Organization. Lyon: International Agency for Research on Cancer, 2016: 124-129.

5. Khade S, Shenoy A. Ectopic choroid plexus papilloma. Asian J Neurosurg 2018; 13: 191-194.
6. Kihara A, Lihara K, Murata K, Kitagawa M, Horiuchi $\mathrm{H}$. Choroid plexus papilloma arising in a mature cystic teratoma of the ovary: a short case report and literature review. Pathol Int 2015; 65: 563-565.

7. Shah A, Latoo S, Ahmed I, Malik AH. Head and neck teratomas. J Maxillofac Oral Surg 2009; 8: 60-63.

8. Akbulut M, Kelten EC, Ege CB. Mature cystic teratoma with predominately neurogenic elements case report. Aegean Pathol J 2006; 3: 18-20.

9. Sharma S, Dawson L, Mandal AK. Primary retroperitoneal teratoma with predominant neurogenic elements masquerading as adrenal tumor. Turk J Pathol 2019; 35: 69-73.

10. Williams K, Chernetsova E, Michaud J, El Demellawy D. Neurogenic ovarian vyst: arare, monodermal teratoma. Pediatr Dev Pathol 2015; 18: 341-342.

11. Catala M. Embryonic and fetal development of structures associated with the cerebro-spinal fluid in man and other species. Part I: the ventricular system, meninges and choroid plexuses. Arch Anat Cytol Pathol 1998; 46: 153-169.

12. Ikota H, Tanaka Y, Yokoo H, Nakazato Y. Clinicopathological and immunohistochemical study of 20 choroid plexus tumours: their histological diversity and the expression of markers useful for differentiation from metastatic cancer. Brain Tumor Pathol 2011; 28: 215-221.

13. Hasselblatt M, Böhm C, Tatenhorst L, et al. Identification of novel diagnostic markers for choroid plexus tumors: amicroarray-based approach. Am J Surg Pathol 2006; 30:66-74

14. Von Gunten M, Burger H, Vajtai I. Choroid plexus papilloma developing in a dermoid cyst of ovary. Histopathology 2006; 49: 204-205.

15. Quadri AM, Ganesan R, Hock YL, Karim SN, Hirschowitz L. Malignant transformation in mature cystic teratoma of the ovary: three cases mimicking primary ovarian epithelial tumors. Int J Surg Pathol 2011; 19: 718-723.

16. Dessauvagie BF, Ruba S, Robbins PD. Choroid plexus papilloma arising in a mature cystic teratoma of a 32-year-old female. Pathology 2013; 45: 88-89. 